\title{
Evaluation of interpupillary distance in the Turkish population
}

This article was published in the following Dove Press journal:

Clinical Ophthalmology

3 August 2015

Number of times this article has been viewed

\author{
Yildiray Yildirim ${ }^{\prime}$ \\ Ibrahim Sahbaz ${ }^{2}$ \\ Taner Kar' \\ Gamze Kagan ${ }^{3}$ \\ Mehmet Tolga Taner ${ }^{4}$ \\ Ilker Armagan ${ }^{2}$ \\ Begum Cakici²
}

'Department of Ophthalmology, Gulhane Military Medical Academy Haydarpasa Training Hospital, Istanbul, Turkey; ${ }^{2}$ Department of Opticianry, ${ }^{3}$ Department of Occupational Health and Safety, ${ }^{4}$ Department of Healthcare Management, Uskudar University, Istanbul, Turkey
Correspondence: Yildiray Yildirim Department of Ophthalmology, Gulhane Military Medical Academy Haydarpasa Training Hospital, Tıbbiye Street, Uskudar, 34668, Istanbul, Turkey Email yyildirim@gata.edu.tr
Purpose: The aim of this study was to report normative values and ranges of interpupillary distance (IPD) in different age groups of a Turkish population.

Methods: A total of 756 healthy subjects were included in this prospective study. After a complete ophthalmic evaluation, subjects were divided into four age groups to assess differences between age groups in relation to IPD. The age groups were 20-30, 31-50, 51-70, and 71-89 years. Far IPD measurements were performed using an autorefractometer (Topcon RM-8800).

Results: The mean age was $48.42 \pm 20.55$ years, ranging from 19 to 89 years. The mean IPD was calculated as $62.5 \pm 4.1 \mathrm{~mm}$ (range 49-76). The mean IPD value was observed to be significantly higher among males compared to females $(P<0.001)$. The difference among groups in terms of mean IPD was statistically significant $(P<0.001)$. IPD increased by $4.19 \mathrm{~mm}$ in males and $3.11 \mathrm{~mm}$ in females from the young adults (20-30 years) to older adults (51-70 years), and then a decrease ( 2.6 and $0.19 \mathrm{~mm}$ for males and females, respectively) occurred between 70 and 89 years of age.

Conclusion: The current study offers the population-specific normative data on far IPD in different age groups. Our study showed that sex and age had a significant effect on IPD. Knowledge of normal values in this population subgroup may be useful in studying orbito-cranial growth patterns, syndrome diagnosis, surgical management of cranio-facial deformities and trauma, and manufactures of optical frames and lenses.

Keywords: interpupillary distance, age, sex, Turkish population, refraction

\section{Introduction}

Interpupillary distance (IPD) is the distance between the centers of the pupils and is associated with stereoscopic function. IPD is known to vary according to age, sex, and race. ${ }^{1,2}$ IPD exhibits a parallel increase with the physical development of the individual. A maximum increase in IPD occurs in the first years of life and IPD continues to increase in the early adulthood. ${ }^{2}$ Furthermore, it has been reported that there was also a tendency for greater near esophoria in subjects with near IPD, which was smaller than $62.5 \mathrm{~mm}$, and greater near exophoria in subjects with larger near IPD. ${ }^{3}$

Knowledge of normal IPD values is important in several clinical specialties including ophthalmology, optometry, oculoplastic surgery, genetic, and traumatology. ${ }^{4}$ The normative values of IPD are also important parameter used in lens design and the optic production industry. Eyeglasses and optic device production convenient with the general mean IPD value decreases the eye-related complaints, such as tiredness, headache, and nausea, which are referred to as asthenopia.,

IPD is usually measured as the distance between the centers of pupils (anatomical IPD) or visual axes (physiologic IPD) on both sides. These two values are usually concordant besides being slightly different in some cases. ${ }^{7}$ 
The purpose of this study was to determine the normal anatomical IPD values in different age groups of a Turkish population. In addition, we also assessed the influence of age and refractive status on IPD.

\section{Methods}

A total of 756 healthy subjects were enrolled in this crosssectional study. The healthy subjects were recruited from 948 routine consecutive outpatient visits. One hundred and ninety two patients were excluded from the study as a result of ophthalmologic pathologies. The study was carried out in accordance with the tenets of the Declaration of Helsinki, and was approved by the Clinical Research Ethics Committee of Haydarpasa Numune Training and Research Hospital, Uskudar, Istanbul. Informed consent was obtained from subjects. Healthy individuals aged over 19 years with no eye pathology except refraction disorders were included in the study. Patients with tropia, cornea disorders (dystrophy, ectasia, and central opacities), iris anomalies, pupil shape disorders, cataract and lens disorders, vitreous hemorrhage, retinal detachment, ocular surgery history, orbital trauma or surgery history, orbital inflammation, or tumor history were excluded from the study. No patient had any facial abnormality. All subjects underwent a complete ophthalmological examination. Spherical equivalent (SE) and far IPD measurements were performed using an autorefractometer (Topcon RM-8800, Topcon Corporation, Tokyo, Japan). Near IPD values were not evaluated in this study. The pupillary distance measurement range of the device is between 20 and $85 \mathrm{~mm}$. We adjusted the height of the automatic instrument table so that the patient could sit on the chair with comfort to obtain correct measurement values. The subjects were seated with his or her chin on a chinrest and forehead against the forehead strap and asked to fixate ahead on the target. The measurement was repeated if the patient moved his/her head or eyes.

After the measurement was performed, subjects were divided into four age groups to assess differences between age groups in relation to IPD. The age groups were $20-30$ years $(n=223), 31-50$ years $(n=158), 51-70$ years $(n=252)$, and 71-89 years $(n=123)$, representing young adults, adults, older adults, and elderly adults, respectively. These age groups were selected to compare the current data with those of published data using similar age classification systems.

Data analyses were performed using SPSS 21.0 (IBM Corporation, Armonk, NY, USA). The normal distribution of the considered variables was first evaluated using the ShapiroWilk test. The data are presented as the mean \pm standard deviation for the continuous variables, and the number of cases and percentage was used for the categorical ones. The chi-square test was used for the qualitative data analysis. Differences among groups were tested for significance using the KruskalWallis one-way analysis of variance test. The Mann-Whitney $U$-test was used for comparison of two groups. To explore IPD in relation to the age and refractive status, data were submitted to a multiple linear regression analysis. A $P$-value of $<0.05$ was considered statistically significant.

\section{Results}

In all, 417 (55.16\%) of the patients included in the study were females and 339 (44.84\%) were males, with a mean age of $48.42 \pm 20.55$ years, ranging from 19 to 89 years. The mean age difference between males and females was not significant $(P=0.194)$. The mean IPD was calculated as $62.5 \pm 4.1 \mathrm{~mm}$ (range 49-76). Table 1 shows the demographic and clinical characteristics of subjects.

The mean IPD value was observed to be significantly higher among males compared to females $(P<0.001)$. The mean IPD values according to age groups are shown in Table 2.

The difference among groups was statistically significant $(P<0.001$, the Kruskal-Wallis test $)$. The difference in the mean IPD values was statistically significant between age groups $20-30$ and $31-50$ years, 20-30 and 51-70 years, 20-30 and 71-89 years, and $51-70$ and $71-89$ years $(P<0.001, P<0.001, P<0.001$, and $P=0.034$, respectively, Mann-Whitney $U$-test). There was marginally no significant difference between age groups $31-50$ and $51-70$ years $(P=0.061$, Mann-Whitney $U$-test $)$ and no significant difference between age groups $31-50$ and $71-89$ years $(P=0.676$, Mann-Whitney $U$-test). The differences in the mean IPD values among age groups are shown in Table 3. Multiple linear regression analysis showed that IPD was correlated with the age $\left(R^{2}=0.078, P<0.001\right)$, but was not associated

Table I Demographic and clinical characteristics of the subjects

\begin{tabular}{llll}
\hline & Mean \pm SD & Minimum & Maximum \\
\hline Age (years) & & & \\
$\quad$ Female & $49.3 \pm 20.6$ & 19 & 89 \\
$\quad$ Male & $47.2 \pm 20.7$ & 19 & 88 \\
IPD (mm) & & & \\
$\quad$ Female & $61.4 \pm 3.7$ & 49 & 75 \\
$\quad$ Male & $63.9 \pm 4.4$ & 52 & 76 \\
Refractive status (SE) & & & \\
$\quad$ Right & $0.52 \pm 2.33$ & $-9.75 \mathrm{D}$ & $+9.50 \mathrm{D}$ \\
$\quad$ Left & $0.69 \pm 2.62$ & $-9.75 \mathrm{D}$ & $+13.50 \mathrm{D}$ \\
\hline
\end{tabular}

Abbreviations: SD, standard deviation; IPD, interpupillary distance; SE, spherical equivalent; D, diopter. 
Table 2 Mean interpupillary distance $(\mathrm{mm})$ values in various age groups

\begin{tabular}{lllll}
\hline $\begin{array}{l}\text { Age group, Female } \\
\text { years }(\mathbf{n})\end{array}$ & $\begin{array}{l}\text { Male } \\
(\text { mean } \pm \text { SD) } \\
(\text { mean } \pm \text { SD) }\end{array}$ & $\begin{array}{l}\text { Total } \\
(\text { mean } \pm \text { SD) }\end{array}$ & $\begin{array}{l}\text { Minimum- } \\
\text { maximum }\end{array}$ \\
\hline $20-30(223)$ & $59.2 \pm 3.1$ & $61.5 \pm 3.8$ & $60.3 \pm 3.7$ & $49-70$ \\
$31-50(158)$ & $62.0 \pm 3.1$ & $64.5 \pm 3.6$ & $63.0 \pm 3.6$ & $55-72$ \\
$51-70(252)$ & $62.3 \pm 3.6$ & $65.7 \pm 4.3$ & $63.8 \pm 4.1$ & $52-76$ \\
$71-89(123)$ & $62.1 \pm 3.8$ & $63.1 \pm 4.3$ & $62.7 \pm 4.1$ & $49-74$ \\
\hline
\end{tabular}

with the refractive status $\left(R^{2}=0.078, P=0.82\right.$ [right eye], $P=0.48$ [left eye]).

\section{Discussion}

Various methods may be used for the measurement of IPD. Holland and Siderov used three methods for the measurement of IPD: Victorin's method, corneal reflection, and the pupillometer. They have demonstrated that there are only slight differences between measurements performed with these three techniques. They reported that these differences are too small to be clinically considered in most of the patients. ${ }^{8}$ However, the pupillometer measurement is thought to be the gold standard. ${ }^{9}$ The autorefractometer was used as the fourth method in a study conducted in Iran. ${ }^{1}$ The far IPD is measured when the eyes are focused at optical infinity. The autorefractometer allows us to measure the far IPD and refractive errors at the same visit. Therefore, an automatic refractometer was used in our study.

In a study about IPD comparing the anatomical and physiological IPD values, the anatomical IPD was found to be $0.1-0.3 \mathrm{~mm}$ larger than the physiological IPD, and the physiological monocular components of physiological IPD are recommended to be used for ophthalmic procedures. ${ }^{7}$ Knowledge of the normal IPD values could be helpful for the diagnosis of some type of syndromes such as ocular hypertelorism, Waardenburg syndrome, and Down syndrome. ${ }^{10-12}$

Our result showed that the mean IPD values measured among males were larger than females in all age groups

Table 3 The differences in the mean IPD values among age groups

\begin{tabular}{|c|c|c|}
\hline $\begin{array}{l}\text { Age groups } \\
\text { (years) }\end{array}$ & $\begin{array}{l}\text { Mean IPD values }(\mathrm{mm}) \\
(\text { mean } \pm \text { SD) }\end{array}$ & $P$-value \\
\hline $20-30$ versus $3 \mathrm{I}-50$ & $60.3 \pm 3.7$ and $63.0 \pm 3.6$ & $<0.001$ \\
\hline $20-30$ versus $5 I-70$ & $60.3 \pm 3.7$ and $63.8 \pm 4.1$ & $<0.001$ \\
\hline $20-30$ versus $7 I-89$ & $60.3 \pm 3.7$ and $62.7 \pm 4.1$ & $<0.001$ \\
\hline $3 \mathrm{I}-50$ versus $5 \mathrm{I}-70$ & $63.0 \pm 3.6$ and $63.8 \pm 4.1$ & 0.061 \\
\hline $3 I-50$ versus $7 I-89$ & $63.0 \pm 3.6$ and $62.7 \pm 4.1$ & 0.676 \\
\hline $5 \mathrm{I}-70$ versus $7 \mathrm{I}-89$ & $63.8 \pm 4.1$ and $62.7 \pm 4.1$ & 0.034 \\
\hline
\end{tabular}

Abbreviation: IPD, interpupillary distance. which are similar to other studies. In a study conducted in subjects aged 1 month-19 years in the USA, the IPD value of males was found to be $1.58 \mathrm{~mm}$ higher than that in females. ${ }^{13}$ Another study in subjects aged between 5 and 17 years in the People's Republic of China reported that IPD values of males were higher than that in females. ${ }^{14}$ In a similar study conducted in adult Caucasian subjects between 41 and 80 years of age, the IPD value of adult males was also larger than that in females. ${ }^{15}$ When our results are compared to other studies conducted in neighboring countries, the IPD was calculated (between 19 and 80 years of age) as $61.1 \pm 3.5 \mathrm{~mm}$ in females and $63.6 \pm 3.9 \mathrm{~mm}$ in males in Iran. ${ }^{1}$ In another study conducted in subjects aged between 5 and 55 years in Arab countries, the IPD value of males was $2 \mathrm{~mm}$ higher than that in females. ${ }^{10}$ However, Gupta reported that sex did not usually influence the normal values for IPD in a normal Indian population aged 3-80 years. ${ }^{16}$ The current study also demonstrated that IPD increased by $4.19 \mathrm{~mm}$ in males and $3.11 \mathrm{~mm}$ in females from the young adults (20-30 years) to older adults (51-70 years), and then a decrease $(2.6$ and $0.19 \mathrm{~mm}$ for males and females, respectively) occurred between 70 and 89 years of age. This result can be explained by orbital involutional changes and the increased laxity of soft tissues in the elderly subjects. ${ }^{17}$ Several studies reported an increase in far IPD with age in both males and females. ${ }^{7,10,13,15}$ Fesharaki et al. reported that mean IPD increased $4.8 \mathrm{~mm}$ during the second decade, $1.7 \mathrm{~mm}$ during the third decade, and $0.6 \mathrm{~mm}$ during the fourth and fifth decades of life. ${ }^{1}$ Osuobeni and al-Musa reported that the average IPD of the male children (between 5 and 15 years of age) was greater than females (between 7 and 15 years of age), but the increase in IPD was faster in female children than males. ${ }^{10}$ They demonstrated that IPD increases faster in males after 16 years of age. Evereklioğlu et al. found that there was a significant increase in IPD measurements with age until 19 years in males and 14 years in females. ${ }^{18}$ This difference may be due to the earlier maturation of females than males.

There are several studies about IPD values in the Turkish population. Evereklioğlu et al conducted a study in the Turkish population aged between 7 and 40 years, and they reported the overall mean IPD values for distant to be $60.76 \pm 4.04 \mathrm{~mm}$ in males and $59.46 \pm 3.51 \mathrm{~mm}$ in females. ${ }^{18}$ Since pediatric population included in this study, the overall mean IPD values were lower than our results. However, they reported the mean IPD for 26-40 years age group to be $64.26 \pm 3.00 \mathrm{~mm}$ in males and $62.25 \pm 2.66 \mathrm{~mm}$ in females and these values were similar to our results. Different from this study, we also assessed the IPD in much older subjects ( $40-89$ years). 
IPD values are also important in opticianry. The image quality is decreased, caused by spheric aberration, chromatic aberration, distortion coma, and marginal astigmatism occurring on the lenses as a result of ignorance of IPD during the placement of eyeglasses. Convergence and near focus become harder because of the increased IPD and loss of accommodation ability with time. ${ }^{19}$

\section{Conclusion}

The current study offers the population-specific normative data on IPD in different age groups. Knowledge of normal values in this population subgroup may be useful in studying orbito-cranial growth patterns, syndrome diagnosis, surgical management of cranio-facial deformities and trauma, and manufactures of optical frames and lenses.

\section{Disclosure}

The authors report no conflicts of interest in this work.

\section{References}

1. Fesharaki H, Rezaei L, Farrahi F, Banihashem T, Jahanbakhshi A. Normal interpupillary distance values in an Iranian population. $J$ Ophthalmic Vis Res. 2012;7(3):231-234.

2. Patil SB, Kale SM, Math M, Khare N, Sumeet J. Anthropometry of the eyelid and palpebral fissure in an Indian population. Aesthet Surg J. 2011; 31(3):290-294.

3. Alanazi SA, Alanazi MA, Osuagwu UL. Influence of age on measured anatomical and physiological interpupillary distance (far and near), and near heterophoria, in Arab males. Clin Ophthalmol. 2013;7:711-724.

4. Bogren HG, Franti CE, Wilmarth SS. Normal variations of the position of the eye in the orbit. Ophthalmology. 1986;93(8):1072-1077.

5. Kim SH, Suh YW, Song JS, et al. Clinical research on the ophthalmic factors affecting 3D asthenopia. J Pediatr Ophthalmol Strabismus. 2012; 49(4):248-253.
6. Anderson AL. Accurate clinical means of measuring intervisual axis distance. AMA Arch Ophthalmol. 1954;52(3):349-352.

7. Osuobeni EP, al-Fahdi M. Differences between anatomical and physiological interpupillary distance. J Am Optom Assoc. 1994;65(4): 265-271.

8. Holland BJ, Siderov J. Repeatability of measurements of interpupillary distance. Ophthalmic Physiol Opt. 1999;19(1):74-78.

9. McMahon TT, Irving EL, Lee C. Accuracy and repeatability of selfmeasurement of interpupillary distance. Optom Vis Sci. 2012;89(6): 901-907.

10. Osuobeni EP, al-Musa KA. Gender differences in interpupillary distance among Arabs. Optom Vis Sci. 1993;70(12):1027-1030.

11. Evereklioglu C, Doganay S, Er H, et al. Interpupillary index: a new parameter for hypo-hypertelorism. J Craniomaxillofac Surg. 2001;29(4): 191-194.

12. Juberg RC, Sholte FG, Touchstone WJ. Normal values for intercanthal distances of 5- to 11-year-old American blacks. Pediatrics. 1975;55(3): 431-436.

13. MacLachlan C, Howland HC. Normal values and standard deviations for pupil diameter and interpupillary distance in subjects aged 1 month to 19 years. Ophthalmic Physiol Opt. 2002;22(3):175-182.

14. Zhang M, Hong R, Fu Z, Ye M, Yang H. The measurement of normal values of exophthalmos, interpupillary distance and interorbital distance of children and adolescence in Xiamen and the rule of their development. Zhonghua Yan Ke Za Zhi. 2000;36(6):462-466.

15. Pointer JS. The interpupillary distance in adult Caucasian subjects, with reference to 'readymade' reading spectacle centration. Ophthalmic Physiol Opt. 2012;32(4):324-331.

16. Gupta VP, Sodhi PK, Pandey RM. Normal values for inner intercanthal, interpupillary, and outer intercanthal distances in the Indian population. Int J Clin Pract. 2003;57(1):25-29.

17. Fledelius HC, Stubgaard M. Changes in eye position during growth and adult life as based on exophthalmometry, interpupillary distance, and orbital distance measurements. Acta Ophthalmol (Copenh). 1986; 64(5):481-486.

18. Evereklioglu C, Doganay S, Er H, Gündüz A. Distant and near interpupillary distance in 3448 male and female subjects: final results. Turgut Özal Tip Merkezi Dergisi. 1999;6(2):84-91.

19. Wu KH, Tsai FJ, Li TC, Tsai CH, Peng CT, Wang TR. Normal values of inner canthal distance, interpupillary distance and palpebral fissure length in normal Chinese children in Taiwan. Acta Paediatr Taiwan. 2000; 41(1):22-27.
Clinical Ophthalmology

\section{Publish your work in this journal}

Clinical Ophthalmology is an international, peer-reviewed journal covering all subspecialties within ophthalmology. Key topics include: Optometry; Visual science; Pharmacology and drug therapy in eye diseases; Basic Sciences; Primary and Secondary eye care; Patient Safety and Quality of Care Improvements. This journal is indexed on Submit your manuscript here: http://www.dovepress.com/clinical-ophthalmology-journal

\section{Dovepress}

PubMed Central and CAS, and is the official journal of The Society of Clinical Ophthalmology (SCO). The manuscript management system is completely online and includes a very quick and fair peer-review system, which is all easy to use. Visit http://www.dovepress.com/ testimonials.php to read real quotes from published authors. 